\section{(6) OPEN ACCESS}

\title{
Impact of acute otitis media clinical practice guidelines on antibiotic and analgesic prescriptions: a systematic review
}

\author{
Yelin Deniz, ${ }^{1}$ Rick T van Uum, ${ }^{1}$ Marieke L A de Hoog, ${ }^{1}$ Anne G M Schilder, ${ }^{1}{ }^{1}$ \\ Roger A M J Damoiseaux, ${ }^{1}$ Roderick P Venekamp ${ }^{1}$
}

\begin{abstract}
- Additional material is published online only. To view please visit the journal online (http://dx.doi.org/10.1136/ archdischild-2017-314103)

${ }^{1}$ Julius Center for Health Sciences and Primary Care, University Medical Center Utrecht, Utrecht University, Utrecht, The Netherlands 2evidENT, Ear Institute, University College London, London, UK
\end{abstract}

\section{Correspondence to}

Rick T van Uum, Julius Center for Health Sciences and Primary Care, University Medical Center Utrecht, Utrecht University, Utrecht 3508 GA, The

Netherlands;

R.T.vanUum-2@umcutrecht.nl

YD and RTU contributed equally.

Received 13 September 2017 Revised 24 January 2018 Accepted 25 January 2018 Published Online First 3 March 2018

\begin{abstract}
Background Clinical practice guidelines focusing on judicious use of antibiotics for childhood acute otitis media ( $\mathrm{AOM}$ ) have been introduced in many countries around the world.

Objective To systematically review the effects of these guidelines on the prescription of antibiotics and analgesics for children with AOM.

Methods Systematic searches of PubMed, Embase and Cochrane Library from inception to 6 June 2017 using broad search terms. Studies specifically aimed at evaluating the effects of introduction of national AOM practice guidelines on type of antibiotic and/or analgesic prescriptions were included, irrespective of design, setting or language. The Risk Of Bias In Non-randomized Studies of Interventions tool was used to assess risk of bias.
\end{abstract}

Results of 411 unique records retrieved, seven studies conducted in six different countries (France, Italy, Spain, Sweden, UK and USA (twice)) compared data before and after guideline introduction. All studies had an observational design, using longitudinal data of children aged under 15 years ( $n=200-4.6$ million) from either routine care, insurance databases or electronic surveys. Risk of bias of all studies was judged serious to critical. Of the five studies reporting on antibiotic prescription rates, three showed a decline of $5 \%-12 \%$ up to 3 years after guideline introduction and two found no or negligible effect. In one US study, the initial 9\% decline decreased to 5\% after 4-6 years. The recommended first choice antibiotic was prescribed more frequently ( $9 \%-58 \%$ increase) after guideline introduction in four out of five studies reporting on this outcome. Analgesic prescription rates for AOM were reported in one US study and increased from $14 \%$ to $24 \%$ after guideline introduction.

Conclusion Based upon what is published, the effects of introduction of national clinical practice guidelines on antibiotic and analgesic prescribing for children with AOM seem modest at the most.

Registration PROSPERO: CRD42016050976.

\section{INTRODUCTION}

With emerging antimicrobial resistance posing a serious threat to global public health, promoting judicious use of antibiotics has become a top priority for governments worldwide. As a consequence, clinical practice guidelines for common infectious diseases, including acute otitis media (AOM), have been introduced and updated in many countries over the past decades. ${ }^{1}$ Although
AOM guidelines vary regarding specific recommendations across countries, they generally emphasise the importance of accurate diagnosis and adequate analgesia as well as advocating selective antibiotic prescribing. ${ }^{1}$

It has been suggested that guideline adherence for AOM may be suboptimal ${ }^{2}$ due to a variety of factors, such as fear of serious complications and parental pressure to prescribe antibiotics. ${ }^{3}$ In daily practice, antibiotics are commonly prescribed to children with AOM, ranging from around 50\% in the Netherlands ${ }^{4}$ to $80 \%$ in the USA, ${ }^{5}$ whereas analgesics are only recommended in a minority of cases. $^{6}$

However, the true impact of introducing AOM guidelines on prescription of antibiotics and analgesics for children with AOM in daily practice has not been reviewed systematically. We aim to do so and provide an overview of current available studies that compare prescription data before and after national AOM clinical practice guideline introduction.

\section{METHODS}

\section{Search strategy and study selection}

We performed systematic searches of the PubMed, Embase and Cochrane Library databases from inception to 6 June 2017 using database-specific syntaxes of keywords relevant to 'acute otitis media' and 'guidelines' (see online supplementary for full search strategies). After removing duplicates (RefWorks), two reviewers (YD and RTvU) independently screened titles and abstracts for inclusion. Discussion with a third and fourth reviewer (MLAdH and RPV) resolved any discrepancies. We screened reference lists of included studies for additional studies.

We included all original studies, irrespective of design, setting or language, evaluating the effects of the introduction of national clinical practice guidelines on prescription of antibiotics (rate and type) and/or analgesics for children (up to the age of 16 years) with AOM by comparing data before and after guideline introduction. We only included studies in which the time between data collection before and after guideline introduction was less than 5 years; this was to minimise the impact of other factors that may affect AOM epidemiology and subsequent prescription rates, for example, the introduction of pneumococcal conjugate vaccines and anti-smoking campaigns. 


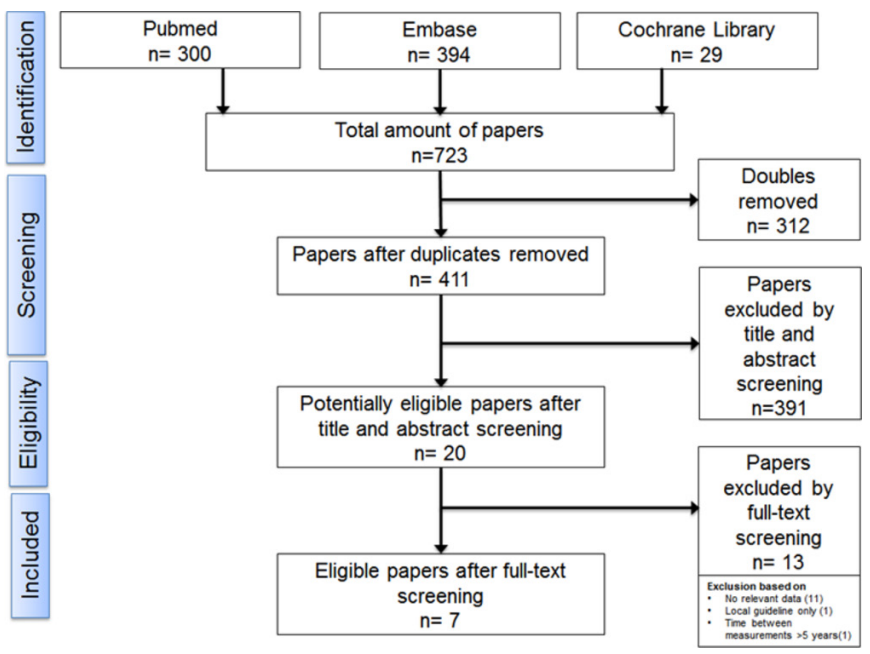

Figure 1 Flow chart.

\section{Data extraction and synthesis}

The primary outcome of interest was the overall antibiotic prescription rate for AOM. Secondary outcomes included type of antibiotic prescribed and analgesic prescription rate.

Two review authors (YD and $\mathrm{RTvU}$ ) independently extracted the following data from the included studies: characteristics of study (year, country, design, setting and data source), study population (number and age of children with $\mathrm{AOM}$ ), guideline details (date of introduction, method of dissemination and management recommendations) and data on our predefined outcomes. Discussion with a third and fourth reviewer (MLAdH and RPV) resolved any discrepancies. To obtain further information on guideline dissemination strategies, we contacted authors of the original publications as well as clinical scientists involved in guideline development in countries subject to this review.

Methodological quality of the included studies was assessed by three reviewers independently (YD, RTvU and RPV) using 'The Risk Of Bias In Non-randomized Studies of Interventions (ROBINS-I) tool', ${ }^{7}$ and any discrepancies were resolved by discussion.

Antibiotic prescription rates, type of antibiotic and analgesic prescription rates before and after introduction of the AOM clinical practice guideline were presented for each study individually. Where before and after guideline introduction data were reported for individual years or subgroups, (such as age), we aimed to calculate averages.

\section{RESULTS}

\section{Search results and study characteristics}

Figure 1 shows the search results; 20 of the 411 unique records were considered potentially relevant. Of these, seven studies ${ }^{8-14}$ were suitable for inclusion in this review. For detailed information of the included studies (see table 1); the seven studies were conducted in six countries: France, Italy, Spain, Sweden, UK and USA (two studies). All were observational studies using longitudinal data of children aged under 15 years; they differed substantially in terms of setting (primary vs secondary care), number of patients ( $\mathrm{n}=200-4.6$ million), study duration (6 months- 10 years longitudinal data) and data source (routine care, insurance databases or electronic surveys).

Table 2 summarises the key guideline recommendations of the included studies. Detailed information on guideline dissemination strategies was obtained for Italy, Sweden, UK and USA (table 3). The method of dissemination varied considerably 
Table 2 Guideline recommendations in included studies

\begin{tabular}{|c|c|c|c|c|c|}
\hline \multirow{2}{*}{$\frac{\text { Study ID }}{\text { Tyrstrup et } a l^{14}}$} & \multirow{2}{*}{$\begin{array}{l}\text { Country } \\
\text { Sweden }\end{array}$} & \multirow{2}{*}{$\begin{array}{l}\text { Year } \\
2010\end{array}$} & \multirow{3}{*}{$\begin{array}{l}\text { Condition } \\
\text { Children 1-12 years with uncomplicated AOM }\end{array}$} & \multicolumn{2}{|c|}{ Guideline recommendation (summary) } \\
\hline & & & & First line & Wait-and-see for 3 days \\
\hline & & & & Second line & Penicillin V (first choice antibiotic) \\
\hline \multirow[t]{3}{*}{ Palma et $a l^{11}$} & Italy & 2010 & Children $>2$ years with uncomplicated, & First line & Analgesics, wait-and-see for 3 days \\
\hline & & & & Second line & $\begin{array}{l}\text { First choice: high-dose amoxicillin ( } 80-90 \mathrm{mg} \text { per kg per day) } \\
\text { Second choice: cephalosporin }\end{array}$ \\
\hline & & & $\begin{array}{l}\text { Children } 6 \text { months-2 years with uncomplicated } \\
\text { AOM Children }>2 \text { years with severe AOM }{ }^{*}\end{array}$ & First line & $\begin{array}{l}\text { First choice: high-dose amoxicillin ( } 80-90 \mathrm{mg} \text { per kg per day) } \\
\text { Second choice: cephalosporin }\end{array}$ \\
\hline \multirow[t]{4}{*}{ Levy et $a l^{9}$} & France & 2011 & Children $>2$ years with uncomplicated AOM & First line & Wait-and-see, reassessment after $48-72$ hours \\
\hline & & & & Second line & High-dose amoxicillin (80-90 mg per kg per day) \\
\hline & & & Children $<2$ years with uncomplicated AOM & First line & High-dose amoxicillin ( $80-90 \mathrm{mg}$ per kg per day) \\
\hline & & & Children $>2$ years with severe $\mathrm{AOM}^{*}$ & Second line & $\begin{array}{l}\text { Amoxicillin/clavulanic-acid or cefpodoxime in case of } \\
\text { treatment failure }\end{array}$ \\
\hline \multirow[t]{3}{*}{ McGrath et allo } & USA & 2004 & Children $>2$ years with uncomplicated, & First line & Analgesics, wait-and-see for 3 days \\
\hline & & & ere AOM & Second line & $\begin{array}{l}\text { First choice: high-dose amoxicillin ( } 80-90 \mathrm{mg} \text { per kg per day) } \\
\text { Second choice: cephalosporin }\end{array}$ \\
\hline & & & $\begin{array}{l}\text { Children } 6 \text { months- } 2 \text { years with uncomplicated } \\
\text { AOM Children }>2 \text { years with severe AOM }{ }^{*}\end{array}$ & First line & $\begin{array}{l}\text { First choice: high-dose amoxicillin ( } 80-90 \mathrm{mg} \text { per } \mathrm{kg} \text { per day) } \\
\text { Second choice: cephalosporin }\end{array}$ \\
\hline \multirow[t]{3}{*}{ Coco et a $\left.\right|^{8}$} & USA & 2004 & Children $>2$ years with uncomplicated, & First line & Analgesics, wait-and-see for 3 days \\
\hline & & & non-severe AOM & Second line & $\begin{array}{l}\text { First choice: high-dose amoxicillin ( } 80-90 \mathrm{mg} \text { per kg per day) } \\
\text { Second choice: cephalosporin }\end{array}$ \\
\hline & & & $\begin{array}{l}\text { Children } 6 \text { months- } 2 \text { years with uncomplicated } \\
\text { AOM Children }>2 \text { years with severe } \text { OMM }^{*}\end{array}$ & First line & $\begin{array}{l}\text { First choice: high-dose amoxicillin ( } 80-90 \mathrm{mg} \text { per kg per day) } \\
\text { Second choice: cephalosporin }\end{array}$ \\
\hline \multirow[t]{3}{*}{ Thompson et al ${ }^{13}$} & UK & $\begin{array}{l}2003 \\
2004\end{array}$ & $\begin{array}{l}\text { Children }>2 \text { years with uncomplicated, } \\
\text { non-severe AOM }\end{array}$ & First line & Analgesics, wait-and-see for $24-72$ hours \\
\hline & & & & Second line & $\begin{array}{l}\text { Amoxicillin thrice daily } 125-250 \mathrm{mg} \text {, for } 5 \text { days } \\
\text { Second choice: erythromycin, azithromycin or clarithromycin }\end{array}$ \\
\hline & & & $\begin{array}{l}\text { Children }<2 \text { years or severe } \mathrm{AOM} \text { or recurrent } \\
\text { infections }\end{array}$ & First line & Amoxicillin thrice daily $125-250 \mathrm{mg}$, for 5 days \\
\hline \multirow[t]{4}{*}{ Rios, et all ${ }^{12}$} & Spain & 2001 & Children $>6$ months with uncomplicated AOM & First line & High-dose amoxicillin for a minimum of 5 days \\
\hline & & & & Second line & $\begin{array}{l}\text { Amoxicillin/clavulanic-acid or ceftriaxone if no response } \\
\text { within } 48-72 \text { hours }\end{array}$ \\
\hline & & & Children $<6$ months with uncomplicated AOM & First line & Amoxicillin/clavulanic-acid or ceftriaxone \\
\hline & & & Children $>6$ months with severe AOM & Second line & $\begin{array}{l}\text { Tympanocentesis and treatment according to results of Gram } \\
\text { staining and antibiotic sensitivity }\end{array}$ \\
\hline
\end{tabular}

*Severe AOM is defined as moderate to severe otalgia with fever $>39^{\circ} \mathrm{C}$.

AOM, acute otitis media; N/A, not available.

across countries, ranging from passive dissemination through online publication or paper copies targeted at individual physicians only to extensive (public) media attention, interactive workshops and joint antibiotic stewardship campaigns.

\section{Risk of bias assessment and study findings}

Risk of bias was judged serious in six studies and critical in one; see figure 2 . The primary and secondary outcome data are illustrated in figures 3 and 4 . Two of the five studies reporting antibiotic prescription rates before and after guideline introduction showed no or a negligible effect. Three studies showed a decline of $5 \%-12 \%$ up to 3 years after guideline introduction.

One US study reported both the short- and long-term impact of guideline introduction; the decline of $9 \%$ in the first 3 years decreased to $5 \%$ after four to 6 years.

In four out of five studies reporting on the type of antibiotic prescribed, prescription of the recommended first choice antibiotic, either amoxicillin or penicillin $\mathrm{V}$, increased by $9 \%-58 \%$ after guideline introduction, with inverse trends for amoxicillin/clavulanic acid which decreased by $7 \%-36 \%$.

Only one US study reported on analgesic prescription rates; this increased from $14 \%$ before to $24 \%$ after guideline introduction.

\section{DISCUSSION}

The introduction of national AOM clinical practice guidelines seems to have at best a modest impact on antibiotic and analgesic prescribing; antibiotic prescription rates decrease by a maximum of $12 \%$ and analgesic rates increase by $10 \%$. Its effect on the type of antibiotic is more substantial with an increase of up to $58 \%$ for the recommended first choice antibiotic.

In line with available literature ${ }^{15}{ }^{16}$ results from the study of Tyrstrup et $a l^{14}$ suggest that tailored guideline dissemination may have a larger impact on antibiotic prescription rates than passive dissemination only. Our findings also indicate that physicians find it easier to substitute rather than refrain from antibiotic prescribing. Reasons include their concerns about the risk of the child falling seriously ill when not prescribing antibiotics, or missing a diagnosis which would have been adequately treated with antibiotics. ${ }^{17}$ This is especially the case when dealing with young children, or in consultations in which physicians perceive parental pressure to prescribe antibiotics. ${ }^{17}$ Apparently, many physicians are either not convinced of, or unfamiliar with, the literature that refutes the risks of restrictive prescribing ${ }^{18}$ and parental expectations of antibiotics. ${ }^{3} 1719$ 


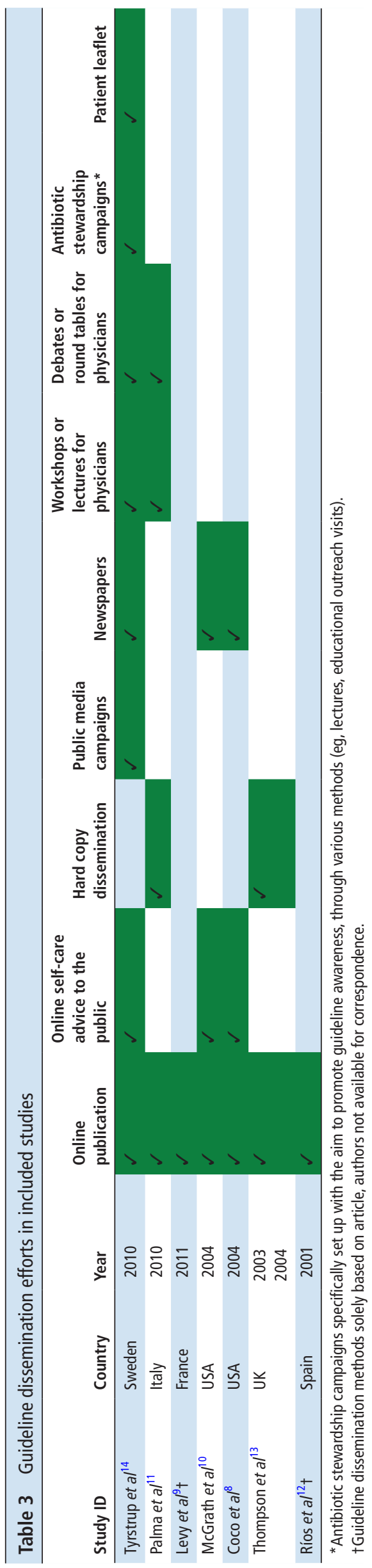

\begin{tabular}{|c|c|c|c|c|c|c|}
\hline 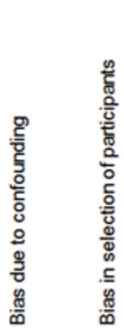 & 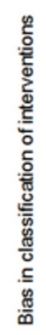 & 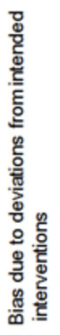 & 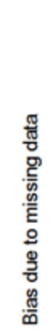 & 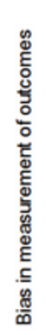 & 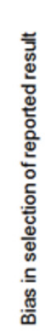 & 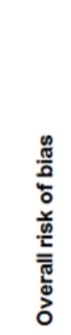 \\
\hline low & $\mathrm{N} /$ & NN & low & low & low & serious \\
\hline low & $\mathrm{N} n$ & $\mathrm{~N} n$ & low & low & low & serious \\
\hline low & Nת & NN & low & low & low & serious \\
\hline low & $\mathrm{N} /$ & $\mathrm{N} n$ & low & low & low & serious \\
\hline low & $\mathrm{N} /$ & Nก & low & low & low & serious \\
\hline low & $\mathrm{N} /$ & NN & low & low & low & serious \\
\hline low & $\mathrm{N} /$ & N/ & low & low & low & critical \\
\hline
\end{tabular}

Figure 2 Risk of bias assessment.

Our findings should be interpreted with some caution. Despite our efforts to minimise the impact of external factors affecting childhood AOM epidemiology and prescribing patterns, such as anti-smoking campaigns, pneumococcal conjugate vaccination and strategies to promote breastfeeding, ${ }^{20} 21$ we cannot rule out this has influenced our results. Also, we were not able to account for ongoing prescribing trends prior to the introduction of the guideline; none of the studies applied interrupted time-series analysis. ${ }^{22}$ Importantly, dissemination of the guideline to the general audience suggesting that parents can manage milder cases of AOM themselves can lead to fewer overall AOM consultations and subsequent antibiotic prescriptions. ${ }^{23}$ Nevertheless, only two out of the seven studies reported on annual fluctuations in AOM consultation rates and none of them accounted for this in their analyses. ${ }^{13}{ }^{14}$ Besides, when parents do self-manage these milder cases of AOM, physicians may be faced with more severe AOM and thus prescribe antibiotics more frequently (leading to a relative increase over time). These aforementioned trends are not captured in the studies. Neither are the phenomena that, with explicit diagnostic guidance, physicians may diagnose AOM more accurately,

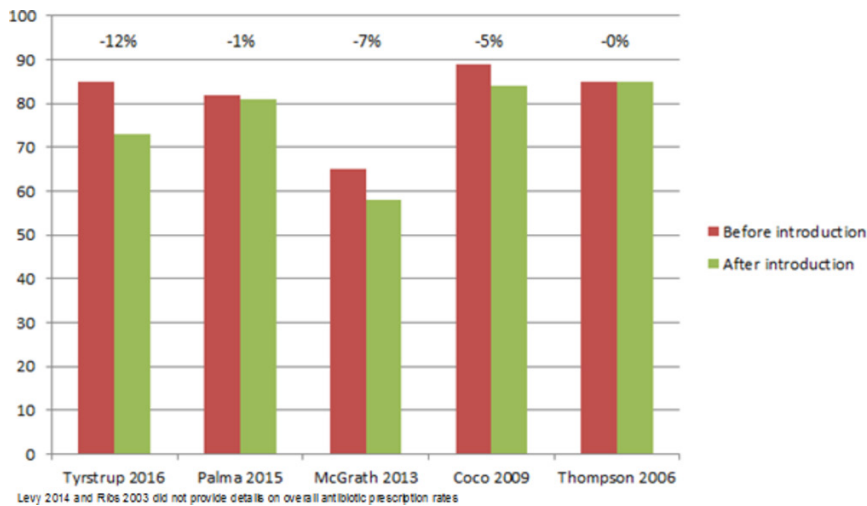

Figure 3 Antibiotics prescription rates. 


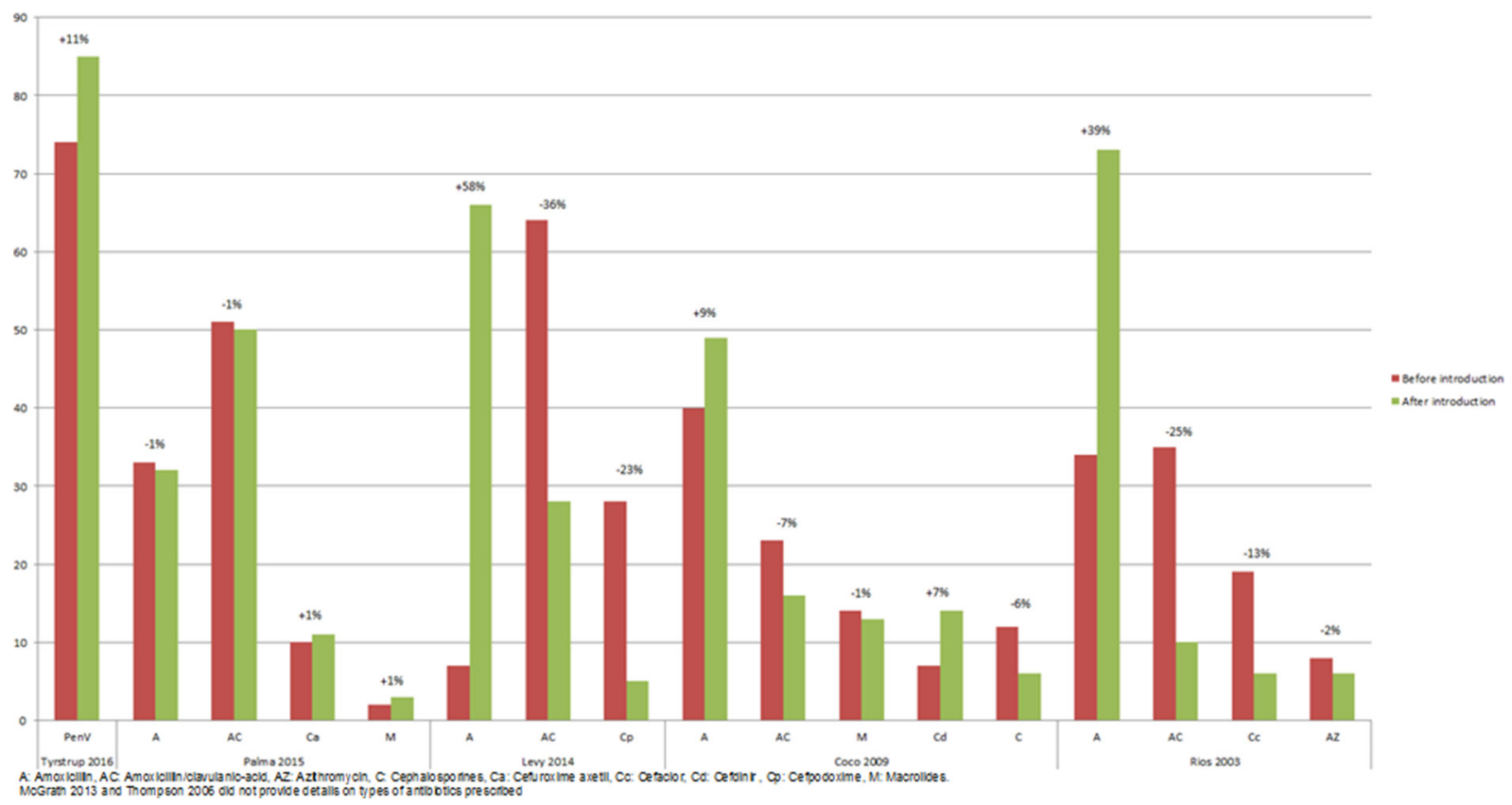

Figure 4 Types of antibiotics prescribed.

leading to fewer overall diagnoses and antibiotic prescriptions, but at the same time a higher prescription rate per diagnosis.

Finally, the vast majority of analgesics for AOM are obtained over-the-counter rather than prescribed. This implies that our results regarding analgesic prescriptions for AOM are incomplete and preclude strong conclusions.

\section{CONCLUSION}

Based on what is published, the introduction of national AOM clinical practice guidelines seems to have at best a modest impact on antibiotics and analgesics prescription rates for childhood AOM. Future studies evaluating the impact of clinical guidelines using longitudinal observational data should use a quasi-experimental approach, and take fluctuations in AOM consultation rates into account, to provide more meaningful estimates on the impact on antibiotic and analgesic prescribing.

Acknowledgements We are grateful to our colleagues P Little (UK), P Marchisio (Italy), R Rosenfeld (USA) and M Tyrstrup (Sweden) for providing information on guideline dissemination in their respective countries.

Contributors YD, RTVU and RPV collected and reviewed primary data. YD and RTVU drafted the first version of the manuscript. All authors revised the manuscript and accepted the final manuscript for publication.

Funding This review was supported by a grant from the Netherlands Organisation for Health Research and Development (ZonMw)—HGOG subprogramme.

Competing interests None declared.

Provenance and peer review Not commissioned; externally peer reviewed.

Open Access This is an Open Access article distributed in accordance with the Creative Commons Attribution Non Commercial (CC BY-NC 4.0) license, which permits others to distribute, remix, adapt, build upon this work non-commercially, and license their derivative works on different terms, provided the original work is properly cited and the use is non-commercial. See: http://creativecommons.org/ licenses/by-nc/4.0/

(c) Article author(s) (or their employer(s) unless otherwise stated in the text of the article) 2018. All rights reserved. No commercial use is permitted unless otherwise expressly granted.

\section{REFERENCES}

1 Ovnat Tamir S, Shemesh S, Oron Y, et al. Acute otitis media guidelines in selected developed and developing countries: uniformity and diversity. Arch Dis Child 2017;102:450-7.

2 Haggard M. Poor adherence to antibiotic prescribing guidelines in acute otitis media-obstacles, implications, and possible solutions. Eur J Pediatr 2011;170:323-32.

3 Lucas PJ, Cabral C, Hay AD, et al. A systematic review of parent and clinician views and perceptions that influence prescribing decisions in relation to acute childhood infections in primary care. Scand J Prim Health Care 2015;33:11-20.

4 van den Broek d'Obrenan J, Verheij TJ, Numans ME, et al. Antibiotic use in Dutch primary care: relation between diagnosis, consultation and treatment. J Antimicrob Chemother 2014:69:1701-7.

5 Grijalva CG, Nuorti JP, Griffin MR. Antibiotic prescription rates for acute respiratory tract infections in US ambulatory settings. JAMA 2009;302:758-66.

6 Pulkki J, Huikko S, Rautakorpi UM, et al. Management of pain in acute otitis media in Finnish primary care. Scand J Infect Dis 2006;38:265-7.

7 Sterne JA, Hernán MA, Reeves BC, et al. ROBINS-I: a tool for assessing risk of bias in non-randomised studies of interventions. BMJ 2016;355:14919.

8 Coco A, Vernacchio L, Horst M, et al. Management of acute otitis media after publication of the 2004 AAP and AAFP clinical practice guideline. Pediatrics 2010;125:214-20.

9 Levy C, Pereira M, Guedj R, et al. Impact of 2011 French guidelines on antibiotic prescription for acute otitis media in infants. Med Mal Infect 2014;44:102-6.

10 McGrath LJ, Becker-Dreps S, Pate V, et al. Trends in antibiotic treatment of acute otitis media and treatment failure in children, 2000-2011. PLoS One 2013:8:e81210.

11 Palma S, Rosafio C, Del Giovane C, et al. The impact of the Italian guidelines on antibiotic prescription practices for acute otitis media in a paediatric emergency setting. Ital J Pediatr 2015;41:37.

12 Ríos L, Mallafré M, González-Hidalgo RM, et al. Aplicación de una pauta terapéutica revisada de otitis media en una consulta pediátrica. Revista de Calidad Asistencial 2003;18:5-8.

13 Thompson PL, Gilbert RE, Long PF, et al. Has UK guidance affected general practitioner antibiotic prescribing for otitis media in children? J Public Health 2008;30:479-86.

14 Tyrstrup M, Beckman A, Mölstad S, et al. Reduction in antibiotic prescribing for respiratory tract infections in Swedish primary care- a retrospective study of electronic patient records. BMC Infect Dis 2016;16:709.

15 Davis $D A$, Thomson MA, Oxman AD, et al. Changing physician performance. A systematic review of the effect of continuing medical education strategies. JAMA 1995:274:700-5.

16 Grimshaw JM, Thomas RE, MacLennan G, et al. Effectiveness and efficiency of guideline dissemination and implementation strategies. Health Technol Assess 2004;8:1-72.

17 Cabral C, Lucas PJ, Ingram J, et al. "It's safer to ... " parent consulting and clinician antibiotic prescribing decisions for children with respiratory tract infections: An analysis across four qualitative studies. Soc Sci Med 2015;136-137:156-64. 


\section{Original article}

18 Van Zuijlen DA, Schilder AG, Van Balen FA, et al. National differences in incidence of acute mastoiditis: relationship to prescribing patterns of antibiotics for acute otitis media? Pediatr Infect Dis J 2001;20:140-4.

19 Butler CC, Rollnick S, Pill R, et al. Understanding the culture of prescribing: qualitative study of general practitioners' and patients' perceptions of antibiotics for sore throats. BMJ 1998:317:637-42.

20 Yilmaz G, Hizli S, Karacan C, et al. Effect of passive smoking on growth and infection rates of breast-fed and non-breast-fed infants. Pediatr Int 2009;51:352-8.
21 Fortanier AC, Venekamp RP, Boonacker CW, et al. Pneumococcal conjugate vaccines for preventing otitis media. Cochrane Database Syst Rev 2014:CD001480.

22 Kontopantelis E, Doran T, Springate DA, et al. Interrupted time-series analysis: a regression based quasi-experimental approach for when randomisation is not an option. BMJ 2015;350:h2750.

23 McWilliams DB, Jacobson RM, Van Houten HK, et al. A program of anticipatory guidance for the prevention of emergency department visits for ear pain. Arch Pediatr Adolesc Med 2008;162:151-6. 